\title{
Analysis of the methylation pattern of six gene promoters in sperm of men with abnormal protamination
}

\author{
Laszlo Nanassy $^{1}$ and Douglas T Carrell ${ }^{1,2,3}$
}

It has recently been shown that alteration of the methylation pattern of imprinted genes is associated with different types of male infertility. The objective of our study was to investigate the methylation pattern of selected gene promoters in sperm of patients with abnormal protamine replacement. The promoters of OCT4, SOX2, NANOG, HOXC11, miR-17 and CREM were analyzed using bisulfite sequencing and the percentage of DNA methylation was compared between patients with an abnormal protamine 1/protamine 2 (P1/ P2) ratio and normozoospermic controls. No significant quantitative differences were found between groups of patients with either an abnormally high or low P1/P2 ratio compared to normal controls. However, two individual samples from infertile subjects (2/20, 10\%) showed an altered methylation pattern for the CREM gene promoter that was not found in control samples. These two samples had a significantly higher $(P<0.05)$ promoter methylation $(5.58$ and $4.23 \%$, respectively) compared to the control group ( $0.46 \%)$. In conclusion, in our pilot study, extreme methylations defects were not seen broadly in severely infertile men. However, two patients exhibited altered methylation of the CREM gene, which may be either causative or a result of abnormal protmaine replacement. Asian Journal of Andrology (2011) 13, 342-346; doi:10.1038/aja.2010.160; published online 3 January 2011

Keywords: Epigenetic; gene promoter; male infertility; methylation; protamine

\section{INTRODUCTION}

Infertility affects $10-15 \%$ of the population and male factor is probably involved in about half of infertility cases. Several classes of male infertility have a well-characterized pathology, but approximately $60 \%$ of the cases are classified as idiopathic. ${ }^{1,2}$ Genetic variations have long been known to account for a considerable fraction of male infertility, and it is likely that the number of the known genetic risk factors will increase in the future. ${ }^{3}$ Along with genetic variations, it is now believed that epigenetic alterations may contribute to a significant percentage of male infertility cases. ${ }^{4}$

Epigenetic marks can affect gene expression without altering the gene coding sequence, and include the methylation of cytosines in the DNA itself. DNA methylation in the promoter region plays an important role in gene expression regulation. ${ }^{5}$ A causative relationship of abnormal promoter methylation of methylenetetrahydrofolate reductase gene with non-obstructed azoospermia has been reported. ${ }^{6}$ In addition several recent studies have revealed an increased abnormal methylation of imprinted loci in men with oligozoospermia ${ }^{7,8}$ and with idiopathic infertility. ${ }^{9}$ There is also evidence that the pattern of DNA methylation at imprinted loci is altered in patients with abnormal protamination. ${ }^{10}$

During spermiogenesis, canonical histones are largely replaced with protamines in a multistep process. This results in a more condensed nucleus that is believed to be important for protecting the sperm chromatin against nucleases and mutagens and enhancing the capability of sperm motility. ${ }^{11,12}$ Two types of protamines, protamine 1 (P1) and protamine 2 (P2), are expressed in most mammals, and in humans the ratio of the incorporation of these is strictly regulated. ${ }^{13}$ Fertile men have a P1/P2 ratio of $1 .{ }^{11,12,14,15}$ Several studies have reported that diminished sperm quality, increased DNA fragmentation and reduced pregnancy rates are associated with an altered protamine ratio. ${ }^{14-21}$ However, the mechanism to explain how abnormal protamination results in altered semen quality and reduced pregnancy rates is not known.

Our laboratory has recently demonstrated that protamine replacement results in an interesting pattern of epigenetic modifications that may poise paternal genes for expression during early embryogenesis. ${ }^{22}$ During the protamine replacement, retained histones are retained at transcription and signaling factors that guide embryo development, at promoters of embryonic developmental genes and at microRNAs. Furthermore, these regions showed a significant DNA hypomethylation. $^{22}$ These data have been supported in two recent papers studying both human and mouse sperm. ${ }^{23,24}$ These studies may indicate that patients with aberrant protamine replacement might also have an altered histone retention localization that could affect the DNA methylation profile on genes important for early embryonic development.

In this pilot study we have studied methylation patterns in the promoters of six genes including a gene involved in spermiogenesis (CREM), a gene from the developmentally important HOX locus (HOXC11), transcription factors (OCT4, SOX2 and NANOG), and a microRNA $(m i R-17)$. These selected genes show diverse promoters

\footnotetext{
${ }^{1}$ Andrology and IVF Laboratories, Department of Surgery, University of Utah School of Medicine, Salt Lake City, UT 84108, USA; ${ }^{2}$ Department of Obstetrics and Gynecology, University of Utah School of Medicine, Salt Lake City, UT 84108, USA and ${ }^{3}$ Department of Physiology, University of Utah School of Medicine, Salt Lake City, UT 84108, USA Correspondence: Dr D T Carrell (douglas.carrell@hsc.utah.edu)
}

Received: 30 August 2010; Revised: 6 October 2010; Accepted: 19 October 2010; Published online: 3 January 2011 
methylation characteristics including those with and without distinct $\mathrm{CpG}$ islands. Ninety-one CpGs per subject in 10 replicates and a total of $27300 \mathrm{CpGs}$ were analyzed. The aim of this study was to evaluate sperm from patients with altered $\mathrm{P} 1 / \mathrm{P} 2$ ratios (both high and low $\mathrm{P} 1 /$ $\mathrm{P} 2$ ratios) for possible changes in the methylation pattern of the promoter regions of these empirically selected genes.

\section{MATERIALS AND METHODS}

\section{Sperm samples and $\mathrm{P} 1 / \mathrm{P} 2$ ratio}

Institutional Review Board approval was obtained before the initiation of the study. Sperm DNA was extracted from 10 normozoospermic, fertile controls, 10 patients with a high $\mathrm{P} 1 / \mathrm{P} 2$ ratio (1.65-3.72) and 10 patients with low $\mathrm{P} 1 / \mathrm{P} 2$ ratio $(0.13-0.64)$. Semen analysis was carried out according to the World Health Organization (2010) standards. ${ }^{25}$ The P1/P2 ratio was determined using acetic acid-urea gel electrophoresis as described previously. ${ }^{17}$

\section{DNA extraction and bisulfite conversion}

Two microgram of extracted DNA of each sample was treated with sodium bisulfite. Briefly, DNA was denatured with $0.2 \mathrm{~mol}^{-1} \mathrm{NaOH}$ at $70{ }^{\circ} \mathrm{C}$ for $15 \mathrm{~min}$, then $30 \mu \mathrm{l}$ of freshly prepared $10 \mathrm{mmol} \mathrm{l}^{-1}$ hydroquinone was added along with $520 \mu \mathrm{l}$ of fresh $3 \mathrm{~mol} \mathrm{l}^{-1}$ sodium metabisulfite ( $\mathrm{pH}$ 5.0). Samples were overlaid gently with mineral oil and incubated for $16 \mathrm{~h}$ at $50{ }^{\circ} \mathrm{C}$ then transferred to a new tube and desalted using PB buffer (Qiagen, Germantown, MD, USA). DNeasy Blood \& Tissue Kit (Qiagen) was used for DNA cleanup. Ethanol traces were removed by centrifugation and the DNA was eluted with $200 \mu$ distilled water. Twenty $\mu \mathrm{l}$ of $3 \mathrm{~mol} \mathrm{l}^{-1} \mathrm{NaOH}$ was added and incubated for $15 \mathrm{~min}$ at $37^{\circ} \mathrm{C}$, and then DNA was precipitated with $22 \mu \mathrm{l} 4 \mathrm{~mol} \mathrm{l}^{-1} \mathrm{NaOAc}$ and $400 \mu \mathrm{l}$ of ice-cold ethanol using tRNA $\left(10 \mu \mathrm{g} \mathrm{ml}^{-1}\right)$ as a carrier. The precipitate was centrifuged at $16000 \mathrm{~g}$ for $60 \mathrm{~min}$ at $4{ }^{\circ} \mathrm{C}$ and resuspended in $30 \mu \mathrm{l}$ of TE ( $\mathrm{pH}$ 8.0). Two $\mu$ l of the sample was used for the amplification of each sequence analyzed.

\section{PCR amplification, cloning and sequencing}

Amplicons from the promoter region of the genes for OCT4, SOX2, NANOG, HOXC11, miR-17 and CREM were amplified by PCR (Table 1). AccuPrime Taq DNA Polymerase System (Invitrogen, Carlsbad, CA, USA) was used according to manufacturer's instructions with a slight modification. Briefly, $50 \mu \mathrm{l}$ reactions were prepared for each gene consisting of $1 \times$ PCR buffer containing $1.5 \mathrm{mmol} \mathrm{l}^{-1}$
$\mathrm{MgCl}_{2}$ and $0.2 \mathrm{mmol} \mathrm{l}^{-1}$ of each dNTP, $0.4 \mu \mathrm{mol}^{-1}$ of each primer, $1 \mu \mathrm{l}$ of Taq polymerase and $1 \times$ PCRx Enhancer solution (Invitrogen). $\mathrm{MgCl}_{2}$ concentration for each PCR reaction is specified in Table 1 . PCR conditions were: initial denaturation $94^{\circ} \mathrm{C}$ for $10 \mathrm{~min} ; 35 \mathrm{amp}$ lification cycles of denaturation at $94{ }^{\circ} \mathrm{C}$ for $30 \mathrm{~s}$, primer annealing at 52-58 ${ }^{\circ} \mathrm{C}$ (Table 1) for $45 \mathrm{~s}$ and strand elongation for $1 \mathrm{~min}$ at $72{ }^{\circ} \mathrm{C}$ followed by a final extension of $10 \mathrm{~min}$ at $72{ }^{\circ} \mathrm{C}$. The size of the PCR products and the number of CpGs analyzed for each amplicon is indicated in Table 1.

Amplicons were cloned using a TOPO TA Cloning kit (Invitrogen) according to manufacturer's recommendations. Ten alleles from positive colonies were sequenced at the University of Utah Core Research Facilities using an ABI 3730xl instrument. For additional technical replicates, five samples from the gene NANOG and five samples from the gene CREM were reamplified, cloned and sequenced.

\section{Data analysis}

The conversion efficiency was checked internally and only sequences with a conversion rate of $95 \%$ or higher were included in data analysis. On the amplicons of SOX2 and CREM, not every CpG was sequenced because the bisulfite conversion produced long poly-T sequences that could not be read. All the statistical analysis was carried out using Stata 9.2 (Stat Corp., College Station, TX, USA). Differences in semen analysis parameters between groups were assessed using analysis of variance. The percentage of methylated $\mathrm{CpGs}$ at each promoter was compared with Kruskal-Wallis test between the three groups. For the comparison of fertile and infertile groups (high and low P1/P2 groups combined), the Mann-Whitney test was used. When comparing a single sample to the control group, the percent methyaltion for each allele was transformed by arc sine transformation and analyzed by one-way analysis of variance. Differences with $P<0.05$ were considered as significant.

\section{RESULTS}

The $\mathrm{P} 1 / \mathrm{P} 2$ ratio was different in all three groups $(P<0.0001)$. The control group had a significantly higher mean $\mathrm{P} 1 / \mathrm{P} 2$ ratio $(0.90 \pm 0.43 ; P<0.0001)$ than the low $\mathrm{P} 1 / \mathrm{P} 2$ group $(0.55 \pm 0.48)$ and a significantly lower $\mathrm{P} 1 / \mathrm{P} 2$ ratio than the high $\mathrm{P} 1 / \mathrm{P} 2$ group $(2.08 \pm 0.20 ; P<0.0001)$. In agreement with previously published data, sperm concentration was the highest in the control group $(132.50 \pm 14.81 ; P<0.05)$. Sperm concentration was not different

Table 1 Parameters of PCR amplifications and characteristics of the selected sequences

\begin{tabular}{|c|c|c|c|c|c|c|}
\hline & Primers $\left(5^{\prime}-3^{\prime}\right.$; forward, reverse) & $\begin{array}{c}\mathrm{MgCl}_{2} \text { concentration } \\
\left(\mathrm{mmol} \mathrm{I}^{-1}\right)\end{array}$ & $\begin{array}{c}\text { Annealing } \\
\text { temperature }\left({ }^{\circ} \mathrm{C}\right)\end{array}$ & $\begin{array}{l}\text { Amplicon } \\
\text { size (bp) }\end{array}$ & $\begin{array}{l}\text { Location from transcription } \\
\text { start site }(+1)\end{array}$ & $\begin{array}{l}\text { No. of analyzed/ } \\
\text { total CpGs }\end{array}$ \\
\hline OCT4 & $\begin{array}{l}\text { AATAGATTTTTGAAGGGGAGTTTAGG } \\
\text { TTCCTCCTTCCTCTAAAAAACTCA }\end{array}$ & 4.0 & 56 & 181 & -1734 to -1553 & $6 / 6$ \\
\hline sox2 & $\begin{array}{l}\text { GTGGTGTGATTTGTTGTTGYGAG } \\
\text { CCTCTTCTTTCTCTCAATCCTAATCTTAAAA }\end{array}$ & 3.5 & 58 & 374 & -685 to -312 & $19 / 20$ \\
\hline$N A N O G^{a}$ & $\begin{array}{l}\text { TTAATTTATTGGGATTATAGGGGTG } \\
\text { AAACCTAAAAACAAACCCAACAAC }\end{array}$ & 4.0 & 58 & 164 & -549 to -385 & $4 / 4$ \\
\hline HOXC11 & $\begin{array}{l}\text { GTTGTGGTATGGAGAGAAGGGG } \\
\text { ACAAAAATTACCCAAATTAACCRAATTAAACA }\end{array}$ & 3.5 & 52 & 337 & -304 to +33 & $19 / 19$ \\
\hline $\operatorname{miR}-17$ & $\begin{array}{l}\text { GAATTATAATGTGAAGAAGGAGGTGTTT } \\
\text { CTTCCTAAAAACCCTACTCTCCC }\end{array}$ & 3.5 & 56 & 461 & -3730 to -3269 & $17 / 17$ \\
\hline CREM & $\begin{array}{l}\text { GGAGGAAAAGGGTTATTAGTTAAGGTATG } \\
\text { CAAAAATAAAACRCCACAATCCAACAATA }\end{array}$ & 3.5 & 58 & 493 & -492 to $+1^{b}$ & $26 / 30$ \\
\hline
\end{tabular}

SOX forward primer contains a $\mathrm{Y}(=\mathrm{C}$ or $\mathrm{T})$ and $\mathrm{CREM}(\mathrm{G}$ or $\mathrm{A})$ reverse primer contains an $\mathrm{R}$.

${ }^{a}$ Primers are published by Deb-Rinker et al.. ${ }^{38}$

${ }^{\mathrm{b}}$ Has multiple transcription start sites; coordinate is in reference to the first exon. 
between the high and low P1/P2 groups. Sperm motility was similar across the different groups. Normal head morphology was reduced in the high and low $\mathrm{P} 1 / \mathrm{P} 2$ groups compared to the control groups $(P<0.001$; Table 2).

Our technical replicates were in good accordance with the initial methylation data with exception of one sample that was therefore removed from further analysis. We did not find any significant difference in the frequency of DNA methylation between the three groups for any of the genes analyzed. Also, no difference was observed between the fertile control group and the combined infertile group in any of the gene promoters investigated (Table 3).

Although groups did not differ, we found an interesting methylation pattern on the promoter of CREM in two infertile patients (Figure 1). Samples from patient \#4 and patient \#19 were significantly different from the control group $(P=0.0005$ and $P=0.0412$, respectively). Sample \#4 is from a subject that had a P1/P2 ratio of 2.04 and low motility but normal sperm count. Sample \#19 was a patient that had a P1/P2 ratio of 0.59 and severe oligoasthenozoospermia.

\section{CONCLUSIONS}

Our study focused on a population of infertile men with aberrant protamine replacement of histones during spermiogenesis. It has previously been shown that generally these patients have lower sperm concentrations and motility than fertile men, and a higher frequency of abnormal sperm morphology and DNA damage than fertile controls.(14-17,19-21) Furthermore, lower pregnancy rates have also been reported in patients with abnormal protamine replacement, even when intracytoplasmic sperm injection is performed. ${ }^{15,17,18,21}$ Whether aberrant protamination is the cause of infertility or simply an indication of other abnormalities during spermatogenesis is not known. Additionally, the possible causes of abnormal embryogenesis resulting in lower in vitro fertilization pregnancy rates have not been evaluated beyond the possible effects of elevated DNA damage. The purpose of this study was to evaluate one possible cause of altered embryogenesis, epigenetic marking via DNA methylation of gene

Table 2 Sperm parameters in the study groups

\begin{tabular}{lcccc}
\hline & Control & High P1/P2 & Low P1/P2 & P value \\
\hline P1/P2 & $0.90 \pm 0.43$ & $2.08 \pm 0.20$ & $0.55 \pm 0.48$ & $0.0001^{\mathrm{a}}$ \\
Concentration $\left(\times 10^{6} \mathrm{ml}^{-1}\right)$ & $132.50 \pm 14.81^{\mathrm{b}}$ & $60.37 \pm 9.56$ & $69.31 \pm 24.45$ & 0.0167 \\
Motility (\%) & $50.00 \pm 2.41$ & $56.20 \pm 6.86$ & $40.80 \pm 6.59$ & 0.1817 \\
Normal head (\%) & $68.67 \pm 4.35^{\circ}$ & $24.20 \pm 3.05$ & $26.56 \pm 5.42$ & 0.0001
\end{tabular}

Abbreviation: P1/P2, protamine 1/protamine 2 .

${ }^{a}$ All three groups were significantly different $(P<0.001)$.

${ }^{\mathrm{b}}$ Significantly different from high $(P=0.0011)$ and low $(P=0.0435) \mathrm{P} 1 / \mathrm{P} 2$ groups.

${ }^{\mathrm{c}}$ Significantly different from high and low $\mathrm{P} 1 / \mathrm{P} 2$ groups $(P<0.001)$. promoter regions, in men with altered protamination of the sperm chromatin.

Abnormal methylation of imprinted loci has been reported in infertile men. Kobayashi et al. analyzed seven imprinted loci in sperm of oligozoospermic patients and found severely altered abnormal methylation patterns in both paternal and maternal imprints. ${ }^{7}$ Hypomethylation of $\mathrm{H} 19$ and hypermethylation of MEST were also observed at a higher frequency in oligozoospermic men than in normozoospermic controls. ${ }^{8}$ Our laboratory has reported alterations in the methylation pattern of imprinted loci of not only oligozoopermic patients, but also in the sperm of patients with abnormal P1/P2 ratios. ${ }^{10}$ Poplinsky et al. have also reported abnormal methylation of imprinted genes in the sperm of men with idiopathic infertility. ${ }^{9}$ Lastly, abnormal promoter methylation of non-imprinted genes has also been associated with impaired spermatogenesis. ${ }^{6}$ These studies have consistently found very low levels of methylation abnormalities in the sperm of fertile controls, but have demonstrated that methylation defects are commonly seen in various types of genes analyzed in a broad spectrum of infertility phenotypes.

It has been shown that sperm promoter methylation pattern resembles to those found in pluripotent cell types such as embryonic stem and embryonic germ cells. ${ }^{26}$ Additionally, a bivalent histone modification pattern, similar to that found in embryonic stem cells, has also been reported in sperm at promoters of microRNAs, and at imprinted gene clusters, and transcription and signaling factors that are important for embryonic development. ${ }^{22}$ It is unknown whether the protamine and histone bound regions are the same in patients with normal and abnormal protamination as in fertile men and whether the establishment of epigenetic marks on DNA is somehow regulated by the nucleioprotein pattern. Our hypothesis was that histone retention on promoter regions is crucial for the proper establishment of DNA methylation, and that abnormal protamination might be accompanied, by or causative of, epigenetic changes on non-imprinted genes in these patients, which might explain their cause of infertility or affect development.

With one exception, we selected genes for this study that have important roles in embryo development. OCT4, SOX2 and NANOG are transcription factors that are crucial for the efficient maintenance of the pluripotent state of cells. ${ }^{27} \mathrm{miR}-17$ (also known as $m i R-17-5 p$ ) is a noncoding microRNA belongs to the $m i R-17-92$ cluster. $^{28}$ This cluster has important roles in tissue development and has been implicated in several types of cancer. ${ }^{29}$ HOXC11 has multiple roles including the formation of the central nervous system, the formation of the vertebrae, hindlimb development and the formation of the urogenital system. ${ }^{30}$ HOXC11 mRNA can be found in eight-cell stage embryos and is thought to be the earliest $H O X$ gene in the developing embryo expressed. $^{31}$

Table 3 Overall abnormal promoter methylation in different groups

\begin{tabular}{|c|c|c|c|c|c|c|}
\hline & Normal P1/P2 $(\mathrm{n}=10)$ & High P1/P2 $(\mathrm{n}=10)$ & Low P1/P2 $(\mathrm{n}=10)$ & $\begin{array}{c}\text { Combined } \\
\text { infertile group }\end{array}$ & & $\mathrm{P}$ value \\
\hline & \multicolumn{4}{|c|}{ Overall abnormal methylation (\%) } & Between all groups & Fertile versus infertile groups \\
\hline sox2 & 0.50 & 0.28 & 0.17 & 0.22 & 0.4304 & 0.2371 \\
\hline NANOG & $13.89^{\mathrm{a}}$ & 10.50 & 14.00 & 12.25 & 0.9904 & 0.9431 \\
\hline HOXC11 & 0.58 & 0.58 & 0.37 & 0.47 & 0.4802 & 0.5003 \\
\hline
\end{tabular}

Abbreviation: P1/P2, protamine 1/protamine 2.

${ }^{a}$ Only nine donor samples were included in the analysis. 
Control Group

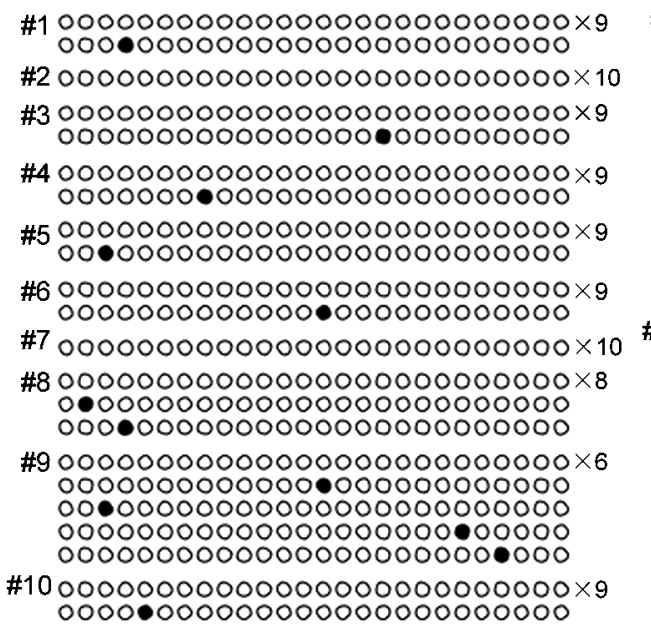

Patient Group

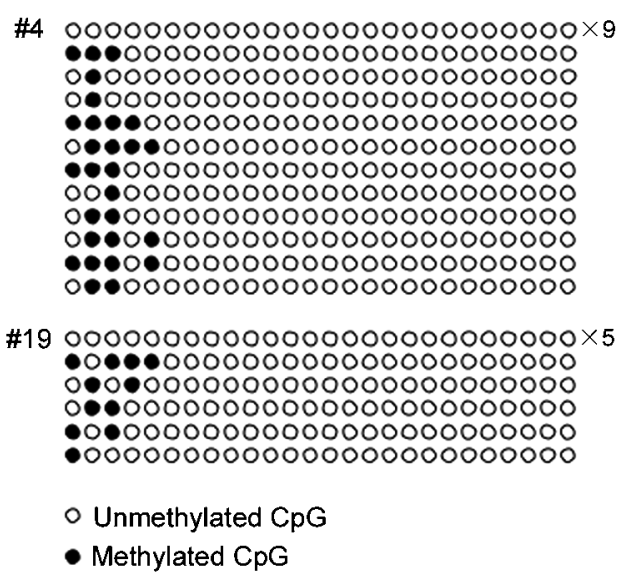

Figure 1 The promoter methylation profile of the CREM in the control group and in patients \#4 and \#19. The number to the right of each profile indicates the number of alleles with the same methylation pattern.

These genes promoters show different methylation characteristics. SOX2 and miR-17 are hypomethylated and both have distinct CpG islands over $100 \mathrm{bp}$ in size with observed/expected $\mathrm{CpG}$ ratio $>0.6$ and CG content $>50 \%$. HOXC11 is also hypomethylated, and its promoter region has no CpG island but has several CpGs. OCT4 and NANOG are both methylated in sperm and their promoters $1 \times$ PCRx Enhancer solution (Invitrogen) do not contain CpG islands.

The paternal genome undergoes active demethylation following fertilization that erases most of the epigenetic marks that are established in spermatogenesis. ${ }^{32,33}$ The purpose of this methylation reprogramming is not understood, but it is possible that it is required for the embryo to achieve totipotency. ${ }^{34}$ It has been recently proposed that promoters in sperm do not undergo extensive genome-wide methylation reprogramming at fertilization. Demethylation likely occurs on transposons and inter and intragenic regions. ${ }^{26}$

There is a subset of important genes in sperm whose promoters do not show this epigenetic modification resemblance to pluripotent cells. Promoters of NANOG and OCT4 are hypermethylated in sperm and hypometylated in embryonic stem and embryonic germ cells. These key regulators of pluripotency are normally silenced during spermatogenesis, possibly preventing the formation of teratomas. After fertilization these marks needs to be removed in order to achieve pluripotency in the embryo. NANOG has been shown to be demethylated rapidly after fertilization as a result of both active and passive processes. ${ }^{26}$ Thus, abnormalities in the methylation patterns of these genes likely reflect aberrant re-establishment of these epigenetic marks during spermatogenesis rather than a deficiency that will be transmitted to the next generation.

We did not find any significant difference in promoter methylation of the selected developmental genes between the patient group with abnormal protamination and fertile subjects. Our comparison was made based on the number of methylated CpGs, assuming that all the CpGs are of equal importance. It has to be taken account that smaller changes in methylation still might be biologically relevant. Animal models might be useful in understanding the effect of small but possibly meaningful differences in the methylation profile of gene promoters in the future. In this pilot study, we did not find extreme differences between samples from patients with abnormal protamination and known fertile subjects at least in the patients and on the genes we evaluated.

One can argue that the empirical approach we used for the selection of the genes for our study is inefficient and genome-wide studies help for a better selection of target genes. It is, however, expensive and cumbersome to screen genome-wide for genes that are differentially methylated in patients and in controls. Based on the data generated in this study, a genome-wide study is underway in our laboratory to investigate whether differentially methylated gene promoters are randomly localized in the genome or whether they are gene specific. We are also interested in finding possible target genes that are characteristic for abnormal protamination.

Our study population was selected based on the $\mathrm{P} 1 / \mathrm{P} 2$ ratio. Although, abnormal P1/P2 ratio is clearly associated with diminished semen quality, ${ }^{17}$ our study groups showed lower but still normal sperm concentrations and normal motility. Most of the studies that have investigated the methylation status of imprinted control regions reported abnormalities in oligozoospermic men. ${ }^{7,8}$ It is possible that the inclusion of a study group with low sperm count would have given us more information. Future studies will address these questions.

Little is known about the methylation status of spermiogenesis regulatory genes. Also, the expression patterns of these genes in human sperm are not well characterized. For obvious reasons it is very difficult to obtain testicular tissue that could allow us to gain more functional information. CREM is a key transcription factor during spermiogenesis that targets several important genes including P1 and transition protein 1 among others in the process of structuring the spermatozoon. ${ }^{35,36}$ We found no difference in CREM promoter methylation between groups with different $\mathrm{P} 1 / \mathrm{P} 2$ ratios, although we did find two samples with an interesting methylation pattern on the promoter of CREM. It is not known whether these changes could be the underlying reason for their abnormal $\mathrm{P} 1 / \mathrm{P} 2$ ratio and if so, whether these changes are accompanied by other disturbances in the establishment of epigenetic marks. It is possible that abnormal $\mathrm{P} 1 / \mathrm{P} 2$ ratio could be the result of several different types of misregulation during spermiogenesis, and our finding is intriguing with a $10 \%$ frequency in this phenotype, albeit using a small number of patients. However, the analysis of additional samples will be necessary to validate our finding. A 
follow-up study is underway in our laboratory analyzing more patients with an extended target region.

In our study, we analyzed a heterogeneous sperm population. Most of the earlier studies used samples that were fractioned with either density centrifugation ${ }^{8,37}$ or with swim-up. ${ }^{7,9}$ There is no information regarding the methylation status of the whole sample compared to a fractioned sample. However, there is a possibility that the unselected sample can mask differences that might exist between the better quality sperm populations in different samples. We found a very low level of hypermethylation and a moderate level of hypomethylation even in samples with low quality, which contradicts to this theory. Also, comparison of unselected samples resulted in detectable differences analyzing imprinted genes. ${ }^{10}$

In conclusion, while no statistically significant changes in promoter methylation of selected genes were found using bisulfite sequencing comparing patients with protamination abnormalities with controls, we did find a distinct methylation pattern on the promoter of CREM in two patients that need to be followed up in a larger study. It is clear, however, that more robust techniques such as pyrosequencing or promoter methylation array must be employed to be able to detect marginal but possibly meaningful differences in methylation.

\section{AUTHOR CONTRIBUTIONS}

The work presented here was carried out in collaboration between both authors. L.N. and D.T.C. were involved in study design and data analysis. L.N. prepared samples and performed all of the experiments.

\section{COMPETING FINANCIAL INTERESTS}

The authors declare no competing financial interests.

1 Dohle GR, Halley DJ, van Hemel JO, van den Ouwel AM, Pieters MH et al. Genetic risk factors in infertile men with severe oligozoospermia and azoospermia. Hum Reprod 2002; 17: 13-6.

2 Erenpreiss J, Spano M, Erenpreisa J, Bungum M, Giwercman A. Sperm chromatin structure and male fertility: biological and clinical aspects. Asian J Androl 2006; 8: 11-29.

3 O'Flynn O'Brien KL, Varghese AC, Agarwal A. The genetic causes of male factor infertility: a review. Fertil Steril 2010; 93: 1-12.

4 Carrell DT, Hammoud SS. The human sperm epigenome and its potential role in embryonic development. Mol Hum Reprod 2010; 16: 37-47.

5 Hatada I, Fukasawa M, Kimura M, Morita S, Yamada K et al. Genome-wide profiling of promoter methylation in human. Oncogene 2006; 25: 3059-64.

6 Khazamipour N, Noruzinia M, Fatehmanesh P, Keyhanee M, Pujol P. MTHFR promoter hypermethylation in testicular biopsies of patients with non-obstructive azoospermia: the role of epigenetics in male infertility. Hum Reprod 2009; 24: 2361-4.

7 Kobayashi $\mathrm{H}$, Sato A, Otsu E, Hiura H, Tomatsu C et al. Aberrant DNA methylation of imprinted loci in sperm from oligospermic patients. Hum Mol Genet 2007; 16: 2542-51.

8 Marques CJ, Costa P, Vaz B, Carvalho F, Fernandes S et al. Abnormal methylation of imprinted genes in human sperm is associated with oligozoospermia. Mol Hum Reprod 2008; 14: 67-74.

9 Poplinski A, Tuttelmann F, Kanber D, Horsthemke B, Gromoll J. Idiopathic male infertility is strongly associated with aberrant methylation of MEST and IGF2/H19 ICR1. Int J Androl 2010; 33: 642-9.
10 Hammoud SS, Purwar J, Pflueger C, Cairns BR, Carrell DT. Alterations in sperm DNA methylation patterns at imprinted loci in two classes of infertility. Fertil Steril 2010; 94: 1728-33

11 Oliva R. Protamines and male infertility. Hum Reprod Update 2006; 12: 417-35.

12 Carrell DT, Emery BR, Hammoud S. Altered protamine expression and diminished spermatogenesis: what is the link? Hum Reprod Update 2007; 13: 313-27.

13 Corzett M, Mazrimas J, Balhorn R. Protamine 1: protamine 2 stoichiometry in the sperm of eutherian mammals. Mol Reprod Dev 2002; 61: 519-27.

14 Balhorn R, Reed S, Tanphaichitr N. Aberrant protamine 1/protamine 2 ratios in sperm of infertile human males. Experientia 1988; 44: 52-5.

15 Carrell DT, Liu L. Altered protamine 2 expression is uncommon in donors of known fertility, but common among men with poor fertilizing capacity, and may reflect other abnormalities of spermiogenesis. J Androl 2001; 22: 604-10.

16 Belokopytova IA, Kostyleva EI, Tomilin AN, Vorob'ev VI. Human male infertility may be due to a decrease of the protamine P2 content in sperm chromatin. Mol Reprod Dev 1993; 34: 53-7.

17 Aoki VW, Liu L, Carrell DT. Identification and evaluation of a novel sperm protamine abnormality in a population of infertile males. Hum Reprod 2005; 20: 1298-306.

18 de Mateo S, Gazquez C, Guimera M, Balasch J, Meistrich ML et al. Protamine 2 precursors (Pre-P2), protamine 1 to protamine 2 ratio (P1/P2), and assisted reproduction outcome. Fertil Steril 2009; 91: 715-22.

19 Carrell DT, Emery BR, Liu L. Characterization of aneuploidy rates, protamine levels, ultrastructure, and functional ability of round-headed sperm from two siblings and implications for intracytoplasmic sperm injection. Fertil Steril 1999; 71: 511-6.

20 Aoki VW, Moskovtsev SI, Willis J, Liu L, Mullen JB et al. DNA integrity is compromised in protamine-deficient human sperm. J Androl 2005; 26: 741-8.

21 Aoki VW, Liu L, Jones KP, Hatasaka HH, Gibson M et al. Sperm protamine 1/protamine 2 ratios are related to in vitrofertilization pregnancy rates and predictive of fertilization ability. Fertil Steril 2006; 86: 1408-15.

22 Hammoud SS, Nix DA, Zhang H, Purwar J, Carrell DT et al. Distinctive chromatin in human sperm packages genes for embryo development. Nature 2009; 460: 473-8.

23 Arpanahi A, Brinkworth M, Iles D, Krawetz SA, Paradowska A et al. Endonucleasesensitive regions of human spermatozoal chromatin are highly enriched in promoter and CTCF binding sequences. Genome Res 2009; 19: 1338-49.

24 Brykczynska U, Hisano M, Erkek S, Ramos L, Oakeley EJ et al. Repressive and active histone methylation mark distinct promoters in human and mouse spermatozoa. Nat Struct Mol Biol 2010; 17: 679-87.

25 World Health Organization. WHO Laboratory Manual for the Examination and Processing of Human Semen. 5th ed. Geneva: World Health Organization; 2010.

26 Farthing CR, Ficz G, Ng RK, Chan CF, Andrews S et al. Global mapping of DNA methylation in mouse promoters reveals epigenetic reprogramming of pluripotency genes. PLoS Genet 2008; 4: e1000116.

27 Chambers I, Smith A. Self-renewal of teratocarcinoma and embryonic stem cells. Oncogene 2004; 23: 7150-60.

28 Tanzer A, Stadler PF. Molecular evolution of a microRNA cluster. J Mol Biol 2004; 339: 327-35.

29 Shan SW, Lee DY, Deng Z, Shatseva T, Jeyapalan Z et al. MicroRNA MiR-17 retards tissue growth and represses fibronectin expression. Nat Cell Biol 2009; 11: 1031-8.

30 Hostikka SL, Capecchi MR. The mouse Hoxc11 gene: genomic structure and expression pattern. Mech Dev 1998; 70: 133-45.

31 Li SS, Liu YH, Tseng CN, Singh S. Analysis of gene expression in single human oocytes and preimplantation embryos. Biochem Biophys Res Commun 2006; 340: 48-53.

32 Mayer W, Niveleau A, Walter J, Fundele R, Haaf T. Demethylation of the zygotic paternal genome. Nature 2000; 403: 501-2.

33 Oswald J, Engemann S, Lane N, Mayer W, Olek A et al. Active demethylation of the paternal genome in the mouse zygote. Curr Biol 2000; 10: 475-8.

34 Reik W, Dean W, Walter J. Epigenetic reprogramming in mammalian development. Science 2001; 293: 1089-93.

35 Mali P, Kaipia A, Kangasniemi M, Toppari J, Sandberg M et al. Stage-specific expression of nucleoprotein mRNAs during rat and mouse spermiogenesis. Reprod Fertil Dev 1989; 1: 369-82.

36 Nantel F, Monaco L, Foulkes NS, Masquilier D, LeMeur M et al. Spermiogenesis deficiency and germ-cell apoptosis in CREM-mutant mice. Nature 1996; 380: 159-62.

37 Boissonnas CC, Abdalaoui HE, Haelewyn V, Fauque P, Dupont JM et al. Specific epigenetic alterations of IGF2-H19 locus in spermatozoa from infertile men. Eur $J$ Hum Genet 2010; 18: 73-80.

38 Deb-Rinker P, Ly D, Jezierski A, Sikorska M, Walker PR. Sequential DNA methylation of the Nanog and Oct-4 upstream regions in human NT2 cells during neuronal differentiation. J Biol Chem 2005; 280: 6257-60. 